Image Article

iMedPub Journals

www.imedpub.com

$10.21767 / 2386-5180.1000232$

\title{
Post Thrombolysis Intracranial Hemorrhage
}

\section{Ayush Dubey*}

Department of Neurology, SAIMS Medical College and PG Institute, Indore, Madhya Pradesh, India

${ }^{*}$ Corresponding author: Ayush Dubey, Department of Neurology, SAIMS Medical College and PG Institute, Indore, Madhya Pradesh, India, Tel: +917999867326; E-mail: ayushdubey2@yahoo.co.in

Received: April 03, 2018; Accepted: April 20, 2018; Published: April 24, 2018

Citation: Dubey A (2018) Post Thrombolysis Intracranial Hemorrhage. Ann Clin Lab Res Vol.6: No.2: 232.

\section{Description}

Intra cranial hemorrhage is a major complication of thrombolytic therapy in acute ischemic stroke which is also associated with high mortality. It typically occurs within 24-36 hours of treatment initiation and is characterized by rapid hematoma development and growth [1]. The most consistently identified predictors of clinically significant ICH in acute revascularization trials have been thrombolytic therapy, dose of lytic agents, edema or mass effect on head CT, stroke severity, and age. Other risk factors may be hyperglycemia, concurrent heparin use, timing of therapy, and timing of successful recanalization [2,3] (Figures 1 and 2).

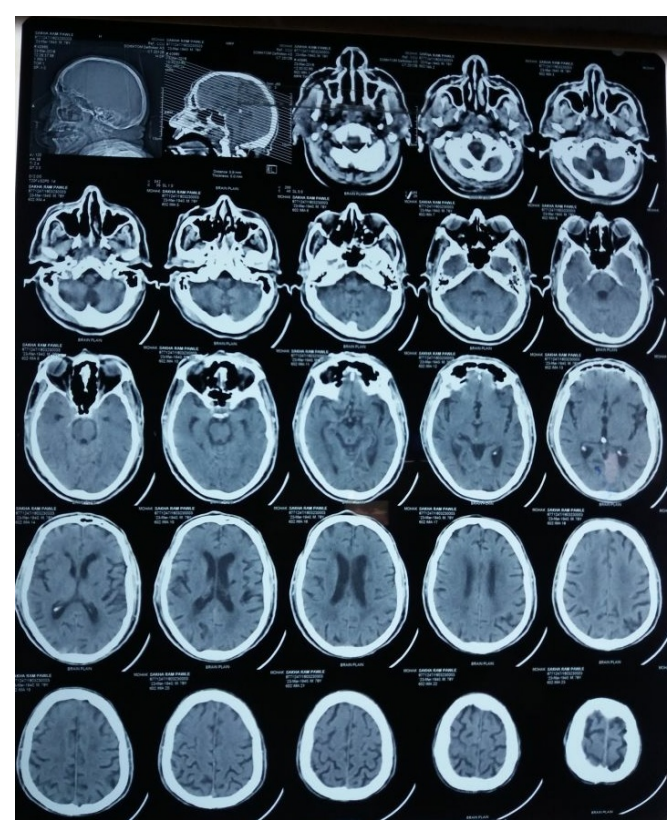

Figure 1 Baseline CT scan done immediately after stroke.

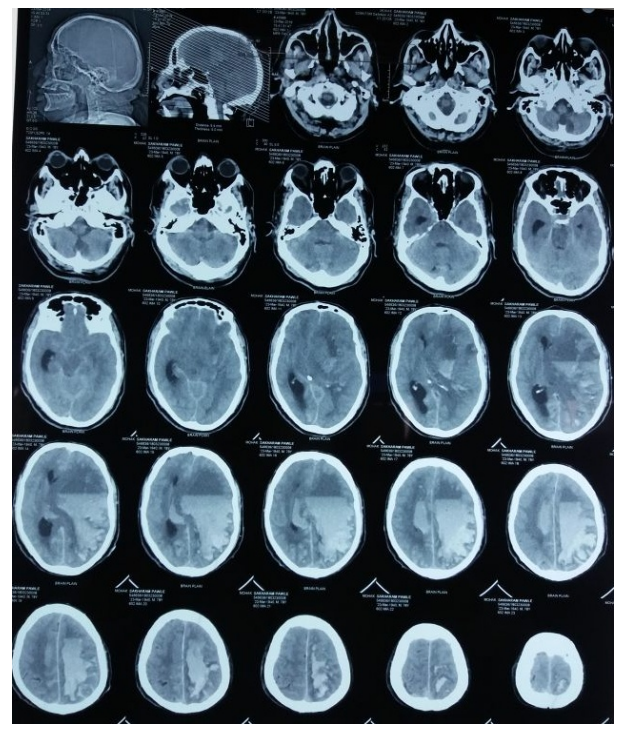

Figure 2 CT scan after tissue plasminogen activator (alteplase) showing massive intracranial hemorrhage in left fronto parietal region.

\section{References}

1. Vinchon M, Noule N, Tchofo PJ, Soto-Ares G, Fourier C, et al. (2004) Imaging of head injuries in infants: temporal correlates and forensic implications for the diagnosis of child abuse. J Neurosurg 101: 44-52.

2. Ashis $P$, Singh $D$, Khandelwal $N$ (2006) Fallacies of routine CT scans in identifying lesions in severe head injury. Ind $\mathrm{J}$ Neurotrauma 3: 36-40.

3. Weber C, Grzyska U, Lehner E, Adam G (2003) Clinical relevance of cranial CT under emergency conditions-basic neuroradiologic investigations. Rofo 175: 654-662. 